\title{
CÉLULAS INFLAMATÓRIAS E SEUS MEDIADORES NA PATOGÊNESE DA DPOC
}

\author{
Cláudia Henrique da Costa*1, Rogério Rufino², José Roberto Lapa e Silva ${ }^{3}$
}

Trabalho realizado no Laboratório Multidisciplinar de Pesquisa da Universidade Federal do Rio de Janeiro - UFRJ - Rio de Janeiro (RJ) Brasil. Hospital Universitário Clementino Fraga Filho. Universidade do Estado do Rio de Janeiro, RJ

\section{*Correspondência:}

Av. 28 de setembro, 77 Secretaria de Pneumologia

e Tisiologia do Hospital

Universitário Pedro Ernesto

$2^{\circ}$ andar

Tel/fax. 55.21.2587-6348

ccosta@uerj.br

\begin{abstract}
RESUMO
A doença pulmonar obstrutiva crônica (DPOC) é causada por processo inflamatório crônico que limita o fluxo aéreo, sendo sua principal causa o tabagismo. Conforme dados da Organização Mundial de Saúde (OMS), a DPOC será a quarta causa de mortalidade em 2020, atrás apenas das doenças vasculares, cardíacas e cerebral, além das neoplasias. Apesar do enorme crescimento da prevalência e da mortalidade da DPOC, não existe nenhuma terapêutica que consiga controlar a evolução da doença estabelecida. 0 processo inflamatório crônico causado pelos gases da fumaça de tabaco desencadeia alterações estruturais que predominam nas pequenas vias aéreas (menores que $2 \mathrm{~mm}$ ). Essa agressão provoca um processo inflamatório que conta com a participação não apenas de macrófagos, linfócitos e neutrófilos, mas células estruturais como epiteliais, musculares e fibroblastos. Atualmente, a interação entre macrófagos e linfócitos, especialmente CD8+, tem sido implicada na patogênese da DPOC. Quimiocinas como CXCL9/MIG, CXCL10/IP-10, CXCL11/I-TAC e CCL5/RANTES têm sido descritas como possíveis responsáveis pelo recrutamento de linfócitos T e monócitos sanguíneos, facilitando o aumento de macrófagos alveolares e linfócitos T CD8 + no parênquima dos pacientes com DPOC. Conhecer melhor como ocorre o tráfego de células mononuclerares em direção ao pulmão é fundamental não só para um maior entendimento da patogênese da DPOC, mas para o desenvolvimento de terapêuticas adequadas. Com base nessas evidências tem sido proposto o estudo de moléculas capazes de bloquear de forma específica o recrutamento de células inflamatórias para o pulmão por meio de ação direta nos seus receptores.
\end{abstract}

UnIteRMOS: DPOC. Inflamação. Quimiocinas.

\section{INTRODUÇÃO}

A doença pulmonar obstrutiva crônica (DPOC) é caracterizada pelo lento e progressivo desenvolvimento de limitação ao fluxo aéreo que é pouco reversível tanto espontaneamente como por meio de medicamentos, o que contrasta com a definição de asma, situação na qual a obstrução brônquica é usualmente revertida por meio do uso de broncodilatadores ${ }^{1}$.

Atualmente, a DPOC é a quarta causa mais comum de óbito nos Estados Unidos, atrás da doença caronariana isquêmica, câncer e doença cerebrovascular ${ }^{2}$. Um amplo estudo epidemiológico conduzido nesse país entre 1988 e 1994, o "third National Health and Nutrition Examination Survey" (NHANES III), avaliou que a prevalência da DPOC na população entre 25 e 75 anos era de $16 \%^{3}$. A Organização Mundial da Saúde, que atualmente estima a existência de 1,1 bilhão de pessoas fumantes, prevê que em 2020 esta doença seja a quarta causa de óbito em todo o mundo ${ }^{4}$. O estudo PLATINO, que avaliou a prevalência da
DPOC na população acima de 40 anos, em cinco cidades latinoamericanas (São Paulo, Santiago, Cidade do México, Montevidéu e Caracas), verificou uma taxa que variou de $7,8 \%$ na Cidade do México a 19,7\% em Montevidéu ${ }^{5}$.

Atualmente, o tabagismo é aceito como o principal fator de risco isolado de desenvolvimento de DPOC. E mais: está relacionado a um risco aumentado de óbito devido a DPOC, carcinoma pulmonar e doença coronariana isquêmica. $O$ aumento de risco está diretamente relacionado à carga tabágica. No entanto, é sabido que menos de $20 \%$ dos fumantes evolui para DPOC clinicamente evidente ${ }^{6}$, o que sugere que haja uma população de tabagistas susceptíveis ao desenvolvimento da doença obstrutiva. A razão pela qual apenas uma minoria dos tabagistas desenvolve resposta inflamatória aos agentes nocivos presentes no cigarro que leva à destruição pulmonar, é ainda fato desconhecido.

Alguns autores demonstraram a presença de linfócitos T e macrófagos na parede das vias aéreas de tabagistas, enquanto

1. Professora adjunta da Disciplina de Pneumologia e Tisiologia da Faculdade de Ciências Médicas da Universidade do Estado do Rio de Janeiro - UERJ, Rio de Janeiro, RJ

2. Professor Adjunto de Pneumologia e Tisiologia da Faculdade de Ciências Médicas da Universidade do Estado do Rio de Janeiro. Chefe da Unidade de Pesquisa do Hospital Universitário Pedro Ernesto/UERJ, Rio de Janeiro, RJ

3. Professor Titular da Disciplina de Pneumologia - Faculdade de Medicina e Hospital Universitário Clementino Fraga Filho - Universidade Federal do Rio de Janeiro UFRJ, Rio de Janeiro, RJ 
que neutrófilos são preferencialmente coletados na luz alveolar? Nesse processo inflamatório existe a participação não apenas das células inflamatórias, mas de células estruturais como epiteliais, musculares e fibroblastos ${ }^{1,8}$. 0 acúmulo de macrófagos e de linfócitos na parede das pequenas vias aéreas tem recebido muito interesse por parte dos pesquisadores da especialidade ${ }^{9,10}$. Diferente do que ocorre na asma, onde existe proliferação de linfócitos T com predomínio de CD4, vários achados apontam para o acúmulo especialmente de linfócitos T CD8 ${ }^{1,10}$. Esta dicotimização do perfil inflamatório, que é particular a cada uma das doenças inflamatórias pulmonares, poderia explicar o aparecimento de mediadores inflamatórios específicos que seriam determinantes no desenvolvimento da lesão estrutural que ocorre na DPOC. Entre os mediadores que causam acúmulo de células no pulmão enfisematoso e que propiciam a manutenção do processo inflamatório, certamente existe um lugar para as quimiocinas relacionadas ao fenótipo 1 de inflamação. CXCL9/MIG, CXCL10/ IP-10, CXCL11/I-TAC e CCL5/RANTES têm sido aventadas como possíveis quimiocinas implicadas no recrutamento de linfócitos T e monócitos sanguíneos, facilitando o aumento de macrófagos alveolares e linfócitos $T$, especialmente CD8, no parênquima dos pacientes com DPOC ${ }^{11,12}$. O reconhecimento do mecanismo pelo qual ocorre o tráfego de células mononuclerares em direção ao pulmão é fundamental não só para um maior entendimento da patogênese da DPOC, mas para o desenvolvimento de terapêuticas adequadas. O bloqueio de receptores específicos que reduzisse o recrutamento de células inflamatórias diretamente relacionadas com a destruição pulmonar pode ser uma proposta interessante de atuação sobre esta doença ${ }^{1}$.

\section{Macrófagos}

Macrófagos representam a maioria das células inflamatórias recolhidas das vias aéreas tanto de pessoas saudáveis quanto de pacientes com DPOC. No entanto, o número de macrófagos está aumentado entre 5 e 10 vezes no lavado broncoalveolar (LBA) de pacientes com DPOC, quando comparado com voluntários não tabagistas ${ }^{1}$. 0 acúmulo de macrófagos nas paredes das vias aéreas e no parênquima pulmonar dos tabagistas que desenvolvem DPOC pode ser explicado tanto pelo prolongamento do tempo de vida da célula no pulmão como pelo aumento do recrutamento de monócitos (seu precursor) da circulação ${ }^{13}$. Alguns trabalhos sugerem que a participação dos macrófagos na patogênese da DPOC tem relação com a sua capacidade de produzir enzimas metaloproteases (MMP) como a MMP-1, MMP-9 e MMP-12 14,15,16,17. Acredita-se que as metaloproteases sejam capazes de degradar proteínas de forma semelhante às enzimas neutrofílicas ${ }^{14}$ e recrutar células inflamatórias da circulação, facilitando sua infiltração nos tecidos lesados ${ }^{15}$. Macrófagos recolhidos do lavado broncoalveolar (LBA) de pacientes com DPOC apresentam aumento da expressão de receptores para MMP-1 e MMP-916, enquanto que tanto camundongos com deficiência de MMP- $12^{16}$ quanto o uso de inibidores de MMP em cobaias $^{18}$ apresentam efeito protetor à exposição à fumaça de cigarro.

Apesar de não se saber exatamente como os macrófagos atuam na DPOC, está claro que, além de quantitativamente aumentados, estas células estão relacionadas com a destruição pulmonar. Avaliando tecido pulmonar biopsiado de pacientes com DPOC foi verificado que as áreas mais destruídas eram circundadas por processo macrofágico e linfocitário ${ }^{19}$.

Estudos do processo inflamatório que ocorre tanto nas vias aéreas quanto na periferia pulmonar de pacientes com DPOC têm demonstrado infiltrados de linfócitos $T$ associados aos macrófagos, fazendo com que os autores sugerissem a interação entre essas células na patogênese da DPOC ${ }^{9,19}$.

É interessante notar que os corticosteroides são ineficazes no controle da inflamação pulmonar que ocorre na DPOC ${ }^{15}$. A liberação in vitro de IL-8, TNF- $\alpha$ e MMP-9 de macrófagos de pessoas não tabagistas ou de tabagistas sem obstrução brônquica pode ser inibida pelo uso de corticosteroides. No entanto, o mesmo não ocorre quando se avaliam os macrófagos de pacientes com $\mathrm{DPOC}^{20}$. As razões para o desenvolvimento de resistência a estes medicamentos em pacientes com DPOC podem ser, pelo menos parcialmente, explicada pela redução da atividade da histona di-acetilase (HDAC) nos macrófagos de pacientes com DPOC ${ }^{21}$.

\section{Linfócitos}

Finkelstein et al. foram os primeiros a observar o aumento de linfócitos T no parênquima pulmonar de pacientes com DPOC 22. Esses autores mostraram, inclusive, a existência de correlação entre o número de linfócitos $T$ e áreas de enfisema ${ }^{22}$. Posteriormente, foi demonstrado que tanto os linfócitos T CD4 (T helper) como os CD8 (citotóxico) estavam aumentados nas vias aéreas e no parênquima pulmonar dos pacientes com DPOC 1,9 .

Existem dois padrões de resposta das células T CD4: T helper 1 (Th1) e T helper 2 (Th2). O primeiro, relacionado com a liberação de interleucina (IL) -2, interferon gama (IFN $\gamma$ ) e fator de necrose tumoral-a (TNF-a); enquanto que o segundo está associado à secreção de IL-4, IL-5, IL-10 e IL-13, à produção de imunoglobulina (Ig) E e IgG4, e se associa com a ativação de mastócitos e eosinófilos. Este é o padrão, por exemplo, da asma ${ }^{23}$.

Assim como as células T CD4, as CD8 também apresentam dicotomia de expressão, neste caso, sendo chamadas de Tc1 (células T citotóxicas do tipo 1 ) e Tc2 (células T citotóxicas do tipo 2). No primeiro padrão, observa-se produção de IFN $\gamma$, mas não de IL-4. No segundo, as células liberam IL-4, mas não INF $\gamma^{23}$.

Os linfócitos T CD4 e CD8 estão aumentados no parênquima pulmonar e na parede das vias aéreas de pacientes com DPOC ${ }^{24}$. Em modelo animal de enfisema induzido pela exposição à fumaça de cigarro foi observado que, além do número de linfócitos $T$ estarem aumentado, havia correlação direta entre esse número e a gravidade da doença pulmonar ${ }^{25}$.

Na DPOC, o interesse está voltado para o padrão Tc1 das células CD8, pois vários artigos demonstram o predomínio dessas células no escarro, no LBA e na biópsia dos pacientes, quando comparado aos tabagistas sem limitação do fluxo aéreo e aos voluntários não tabagistas ${ }^{9,24}$. No entanto, os linfócitos T CD4 também estão aumentados no parênquima de pacientes com DPOC, especialmente naqueles com doença mais grave $^{26}$. Embora o papel destas células ainda esteja obscuro, é possível que elas tenham importância na manutenção da memória imunológica que perpetuaria o processo mesmo após a suspensão do tabagismo ${ }^{1}$.

Linfocitos T CD8 estão aumentados na parede brônquica e no parênquima pulmonar de pacientes com DPOC quando comparado com tabagistas sem obstrução brônquica9 ${ }^{9}$. Mais 
ainda, a intensidade da infiltração linfocitária está diretamente relacionada com o grau de obstrução brônquica ${ }^{19}$. Dessa forma, a proliferação de células T CD8 no pulmão de tabagistas estaria relacionada com a progressão da doença obstrutiva ${ }^{9}$. Uma das funções das células T CD8 é a apoptose de células-alvo, que no caso do enfisema está relacionada com a destruição pulmonar. Foi demonstrada a relação tanto da apoptose quanto da infiltração de células CD8 na parede brônquica com a carga tabágica e com a destruição pulmonar em pacientes com DPOC ${ }^{27}$.

A polarização da inflamação pulmonar da DPOC em favor do tipo 1 resulta na produção e liberação de um determinado tipo de citocinas, especialmente o interferon- $\gamma$, liberado pelos linfócitos CD4 e CD8 e capaz de ativar os macrófagos, que, por sua vez, passam a produzir uma série de citocinas, incluindo IL-12, que mantém a diferenciação de linfócitos desviada para o fenótipo $1^{9}$.

O mecanismo pelo qual os linfócitos T CD8 se acumulam nas paredes das vias aéreas e no parênquima pulmonar dos pacientes com DPOC ainda não está claro. No entanto, o recrutamento de células para o pulmão deve necessitar da ativação linfocitária, que, por sua vez, provavelmente será seguida por adesão e quimiotaxia seletiva. As células T presentes no pulmão apresentam aumento da expressão de receptores CXCR3 e CCR5, relacionados às quimiocinas responsáveis pelo recrutamento de linfócitos $T^{19,28}$. As quimiocinas que atuam no receptor CXCR3 são CXCL9, CXCL10 e CXCL11, enquanto que as relativas ao receptor CCR5 compreendem CCL3, CCL4, CCL5 e CCL11. Todas têm atividade quimiotáxica de linfócitos ${ }^{19,28}$.

\section{Neutrófilos}

A primeira e mais consistente anormalidade encontrada nas vias aéreas de pacientes com DPOC é a infiltração celular da parede e luz brônquicas ${ }^{29}$. Estudos em animais demonstraram que a exposição à fumaça de cigarro promove a proliferação de neutrófilos nas vias aéreas ${ }^{9,30}$. Utilizando modelo de cobaias, Hulbert et al. observaram a ocorrência de edema da mucosa brônquica após 30 minutos e incremento de cinco vezes no número de neutrófilos após seis horas de inalação de fumaça de cigarro ${ }^{30}$. Dessa forma, não é surpreendente que vários autores tenham publicado estudos relatando o aumento de neutrófilos no escarro e no LBA de pacientes com DPOC ${ }^{31,32}$.

Os neutrófilos estão implicados na liberação de citocinas inflamatórias, mediadores lipídicos e enzimas capazes de promover dano tecidual ${ }^{31}$. Além disso, podem promover hipersecreção de muco por meio de efeito secretagogo e pela proliferação de glândulas mucosas ${ }^{33}$.

Desde o advento da tese de que a destruição pulmonar estaria relacionada ao desequilíbrio entre proteases e antiproteases, o neutrófilo foi tido como fator importante para o desencadeamento da doença, já que esse desequilíbrio seria mantido através da liberação de enzimas neutrofílicas, o que ocasionaria o aumento de proteases no pulmão ${ }^{34}$. Estudos em humanos demonstraram o aumento de neutrófilos no pulmão de pacientes com DPOC e relataram o aumento de produtos da elastase na urina e no plasma desses pacientes ${ }^{35}$. Também foi publicado recentemente que 0 volume de fibras elásticas nos alvéolos e pequenas vias aéreas está reduzido nos pacientes com DPOC ${ }^{36}$. No entanto, Rufino et al. demonstraram que a quantidade de fibras elásticas não está reduzida no parênquima pulmonar de pacientes com enfisema quando comparado a controles não tabagistas e sugeriram que as fibras pudessem estar rompidas ou funcionalmente alteradas ${ }^{37}$. A diferença dos dados obtidos pode ser explicada pelas diferentes metodologias empregadas ou pelo perfil de pacientes estudados, mas chamam a atenção para a necessidade de mais estudos.

Apesar de vários autores terem relatado o aumento de neutrófilos nas vias aéreas de pacientes com DPOC, nem todos os trabalhos demonstraram diferença significativa entre o número de neutrófilos recolhidos de tabagistas sem obstrução brônquica e pacientes com DPOC ${ }^{38}$. Esses achados sugerem que, embora a inflamação neutrofílica esteja constantemente presente nos fumantes, ela provavelmente representa uma resposta inespecífica das vias aéreas à agressão causada pelo tabagismo, não estando, necessariamente, relacionada à progressão para DPOC $^{9}$. E mais: seria necessária a ocorrência de interação com macrófagos e linfócitos $T$, os quais desencadeariam resposta inflamatória ampliada e anormal apenas na parcela de tabagistas que desenvolveria quadro clínico de DPOC.

\section{Eosinófilos}

O papel dos eosinófilos na DPOC é incerto. Alguns autores relataram o aumento destas células no escarro e no LBA dos pacientes com DPOC ${ }^{39,40}$, enquanto que outros associaram esse aumento a uma melhor resposta ao uso de corticosteroides ${ }^{41}$, à associação com doença asmática ${ }^{42}$ ou à ocorrência de exacerbação da doença ${ }^{43}$. É interessante o fato de que os níveis das proteínas eosinofílicas estão tão aumentados na DPOC quanto na asma, mesmo quando a contagem de eosinófilos é menor nos pacientes com doença brônquica irreversível, sugerindo que as células tenham degranulado e não possam ser vistas ao microscópio. É possível que esta degranulação acentuada ocorra devido à atuação da elastase neutrofílica, que costuma estar elevada nos pacientes com DPOC e que causa degranulação de eosinófilos ${ }^{44}$.

\section{Células estruturais}

O processo inflamatório da DPOC envolve uma variedade de células inflamatórias e seus mediadores. No entanto, tem sido sugerida a participação das células estruturais na fisiopatologia da doença ${ }^{45}$.

Em um modelo de ratos expostos à fumaça de cigarro foi observado que havia aumento do número de células dendríticas $^{46}$. Outros autores observaram o aumento das células dendríticas na parede das vias aéreas de fumantes com ou sem DPOC ${ }^{47}$.

As células epiteliais podem ser ativadas diretamente pela fumaça de cigarro passando a produzir mediadores inflamatórios como IL-8 e TNF- $\alpha^{48}$. Alteradas pelo processo inflamatório crônico que leva à metaplasia escamosa com frequência, é possível que as células epiteliais deixem de exercer adequadamente seu papel de defesa, facilitando a ocorrência de infecções respiratórias e a liberação de citocinas.

\section{Citocinas}

Todo processo inflamatório é realizado com a participação de células e de seus mediadores. Entre estes, é importante ressaltar a participação das citocinas no processo inflamatório pulmonar, especificamente na DPOC. Essas proteínas estão envolvidas na interação celular. Usualmente, são menores do que $80 \mathrm{KDa}$ e podem ser produzidas por diferentes tipos de 
células ${ }^{49}$. Costumam atuar nas células próximas (função parácrina), embora algumas possam ser efetivas em células distantes (função endócrina) ou ter efeito sobre a própria célula que a produziu (função autócrina) ${ }^{49}$.

As citocinas atuam em células-alvo e podem desempenhar muitas funções: ativação e proliferação celular, quimiotaxia de outras células, imunomodulação, liberação de outras citocinas ou mediadores inflamatórios, favorecer o crescimento e a diferenciação celulares, além de apoptose ${ }^{50}$.

Estas substâncias costumam ser liberadas em padrões específicos, dependendo da patologia. Assim, o padrão de citocinas liberado na DPOC é diferente do observado em pacientes asmáticos ou em outras doenças inflamatórias. Como várias citocinas são liberadas ao mesmo tempo, o efeito sinérgico ou antagônico de uma citocina sobre outra resultará no padrão inflamatório de uma determinada patologia. Determinar o papel de uma citocina na patogenia de uma doença é difícil, já que ela pode ser influenciada (potencializada ou bloqueada) pela ação de outras citocinas liberadas simultaneamente pela mesma célula ou pela célula-alvo após a sua ativação ${ }^{50}$.

As citocinas atuam ligando-se a receptores específicos e regulando a atividade das células-alvo ${ }^{49}$.

É interessante notar que os receptores de citocinas são altamente específicos e costumam estar presentes em pequeno número nas células não ativadas. No entanto, este número aumenta rapidamente após a ativação celular. As citocinas podem interferir na expressão de seus próprios receptores tanto na célula que as produziu como nas células-alvo. Algumas citocinas potencializam ou bloqueiam a ação de outras citocinas por meio de sua atuação na expressão dos receptores. Por exemplo, podemos citar o interferon-gama (IFN- $\gamma$ ), que pode inibir os receptores de TNF- $\alpha$ em macrófagos ou aumentar a expressão de receptores de IL-1 $\beta$ na asma ${ }^{50}$.

Estes importantes mediadores podem ser classificados de acordo com o seu papel no processo inflamatório.

\section{Citocinas pró-inflamatórias}

Estas citocinas são conhecidas pela sua capacidade de induzir a liberação de outras citocinas, ampliando o processo inflamatório. A mais conhecida é a IL-1, ou fator pirogênico, que está presente em praticamente todos os processos inflamatórios. Ela pode ser liberada por vários tipos de células e induz adesão molecular, expressão da molécula de adesão intercelular (ICAM) -1 e da molécula de adesão de célula vascular (VCAM) - $1 .{ }^{50}$

\section{Citocinas anti-inflamatórias}

São citocinas liberadas para controlar o processo inflamatório. 0 principal exemplo deste grupo é a IL-10, que é liberada por monócitos e macrófagos em resposta a estímulos inflamatórios. Na asma, sua liberação pelos macrófagos está reduzida, sugerindo um descontrole do processo inflamatório nesses pacientes ${ }^{51}$. Embora não tenha sido evidenciada uma clara redução desta citocina em pacientes com DPOC, sugere-se que ela tenha papel semelhante ao observado na asma.

\section{Fatores de crescimento}

Proteínas como o fator de crescimento plaquetário (PDGF), o fator de crescimento transformador (TGF)- $\beta$ e o fator de crescimento epidérmico (EGF) são exemplos de citocinas que exercem influência na proliferação de células estruturais como os fibroblastos e células musculares lisas das vias aéreas. Por meio da renovação da matriz proteica podem estar envolvidas no processo de remodelamento brônquico dos pacientes com DPOC $^{49}$.

\section{Quimiocinas}

Estas citocinas de 8 a $10 \mathrm{KDa}$ apresentam importante propriedade quimiotática para leucócitos ${ }^{49}$. A primeira quimiocina, IL-8, foi descrita em 1987. Desde então, mais de 50 proteínas com esta qualidade foram descritas e agrupadas sob a denominação de quimiocina. Quatro grandes famílias foram classificadas, dependendo do número e disposição de moléculas de cisteína na terminação amino da proteína: C, CC, CXC e $\mathrm{CC}^{52}$ (Quadro 1). As duas maiores famílias e que desempenham papel na patogênese da DPOC são CC e CXC. As quimiocinas da família CC estão envolvidas especialmente com a quimiotaxia de eosinófilos, monócitos e linfócitos T. Têm papel importante na asma e também estão presentes em pacientes com DPOC. As quimiocinas da família CXC, como IL-8, oncogene relacionado ao crescimento- $\alpha$ (GRO- $\alpha$ ) e ativador neutrofílico derivado do epitélio (ENA-78) são moléculas quimiotáticas de neutrófilos e têm sido estudadas em pacientes com DPOC ${ }^{49,52}$. Outras quimiocinas desta família, como as que se ligam ao receptor CXCR3, recentemente, têm sido descritas como possíveis recrutadoras de linfócitos $T$ ativados e monócitos sanguíneos ${ }^{53}$ (Quadro 2).

As quimiocinas exercem sua função acoplando-se à proteína $\mathrm{G}$ do receptor expresso na célula inflamatória ${ }^{54}$. Até o momento, 18 receptores de quimiocinas foram identificados. Os receptores CXCR1 ao CXCR5 interagem com as quimiocinas da família CXC, enquanto que a família CC consiste de nove receptores (CCR1 a CCR9). Alguns receptores recebem a ligação de apenas uma quimiocina, como ocorre com o receptor CCR8, que se liga à CCL1. Outros receptores são compartilhados por várias quimiocinas. Esse é o caso, por exemplo, do CXCR3, que se liga a MIG/CXCL9, IP-10/CXCL10 e I-TAC/CXCL11. O contrário também ocorre, com uma quimiocina se acoplando a vários receptores. Assim, RANTES (Regulated on Activation, Normal, T-cell Expressed and Secreted) / CCL5 pode atuar nos receptores CCR1, CCR3 e CCR5. Finalmente, deve-se lembrar que os receptores estão presentes em vários tipos de células e que eles são estimulados em algumas situações específicas, como nas doenças inflamatórias ${ }^{55}$.

\section{Papel das quimiocinas na patogênese da DPOC}

Através da regulação do trânsito de células inflamatórias em direção aos pulmões, as quimiocinas desempenham um papel fundamental no processo inflamatório da DPOC ${ }^{49}$. Algumas quimiocinas estão sendo estudadas há mais tempo e estão mais claramente implicadas ao processo, enquanto outras desempenham papel ainda incerto.

Interleucina (IL) - 8 / CXCL8

É um potente fator quimiotático de neutrófilos e seu nível está aumentado no escarro induzido de pacientes com DPOC em comparação com os controles não tabagistas ${ }^{10}$. 0 nível de IL-8 está relacionado ao número absoluto e relativo de neutrófilos 


\begin{tabular}{|c|c|c|c|c|}
\hline \multicolumn{5}{|c|}{$\begin{array}{c}\text { Quadro } 1 \text { - Receptores de quimiocinas e as respectivas } \\
\text { células que os expressam }\end{array}$} \\
\hline \multirow{2}{*}{ Células } & \multicolumn{4}{|c|}{ Receptores } \\
\hline & $\overline{C X C R}$ & CCR & CX3CR & XCR \\
\hline \multirow{2}{*}{ Neutrófilos } & CXCR1 & & & \\
\hline & CXCR2 & & & \\
\hline \multirow[t]{5}{*}{ Eosinófilos } & CXCR2 & CCR1 & CX3CR1 & \\
\hline & & CCR3 & & \\
\hline & & $\begin{array}{l}\text { CLR1 } \\
\text { CCR3 }\end{array}$ & & \\
\hline & & CCR4 & & \\
\hline & CXCR3 & CCR5 & & \\
\hline \multirow[t]{6}{*}{ Linfócitos T } & CXCR4 & CCR6 & CX3CR1 & XCR1 \\
\hline & CXCR5 CXCR6 & CCR7 & & \\
\hline & & CCR8 & & \\
\hline & & CCR9 & & \\
\hline & & CCR10 & & \\
\hline & CXCR3 & & & \\
\hline \multirow[t]{3}{*}{ Linfócitos B } & CXCR4 & CCR7 & & \\
\hline & CXCR5 & & & \\
\hline & CXCR1 & & & \\
\hline \multirow{4}{*}{ Monócitos } & CXCR2 & CCR2 & & \\
\hline & CXCR3 & CCR5 & CXJCRI & \\
\hline & CXCR4 & & & \\
\hline & CXCR2 & & & \\
\hline \multirow[t]{2}{*}{ Macrófagos } & CXCR3 & $\begin{array}{l}\text { CCRS } \\
\text { CCRO }\end{array}$ & & \\
\hline & CXCR4 & & & \\
\hline \multirow[t]{2}{*}{ Mastócitos } & CXCR1 & CCR3 & & \\
\hline & UXR2 & & & \\
\hline \multirow[t]{3}{*}{ Basófilos } & & CCR3 & & \\
\hline & & CCR2 & & \\
\hline & & CCR5 & & \\
\hline \multirow[t]{3}{*}{ Células dendríticas } & CXCR4 & CCR6 & & \\
\hline & & CCR7 & & \\
\hline & & CCR9 & & \\
\hline
\end{tabular}

no escarro induzido ${ }^{10}$ e está especialmente aumentado nos pacientes com deficiência de $\alpha 1$ - antitripsina ${ }^{56}$ e naqueles com exacerbação brônquica ${ }^{57}$.

Oncogene relacionado ao crescimento (GRO) - $\underline{\alpha} / \mathrm{CXCL1}$

Produzida e liberada por macrófagos alveolares e células epiteliais, GRO- $\alpha$ tem sido implicada na ativação de neutrófilos, monócitos, basófilos e linfócitos T por meio de sua ligação com o receptor $\mathrm{CXCR} 2^{13}$. Sua concentração está aumentada no escarro, mas não no lavado broncoalveolar de pacientes com DPOC em comparação com tabagistas e não tabagistas ${ }^{58}$. É capaz de recrutar monócitos ${ }^{13}$, mecanismo pelo qual deve ocorrer o acúmulo de macrófagos alveolares no pulmão de pacientes com DPOC.

Ativador neutrofílico derivado do epitélio (ENA) -78/CXCL5

Assim como o GRO- $\alpha$, o ENA 78/CXCL5 atua por meio do receptor CXCR2 e está aumentado no LBA de pacientes com DPOC em relação a controles não tabagistas, embora em níveis não superiores àqueles encontrados em fumantes ${ }^{58}$. Foi relatado que a sua expressão nas células epiteliais está aumentada durante as fases de exacerbação da DPOC ${ }^{59}$.

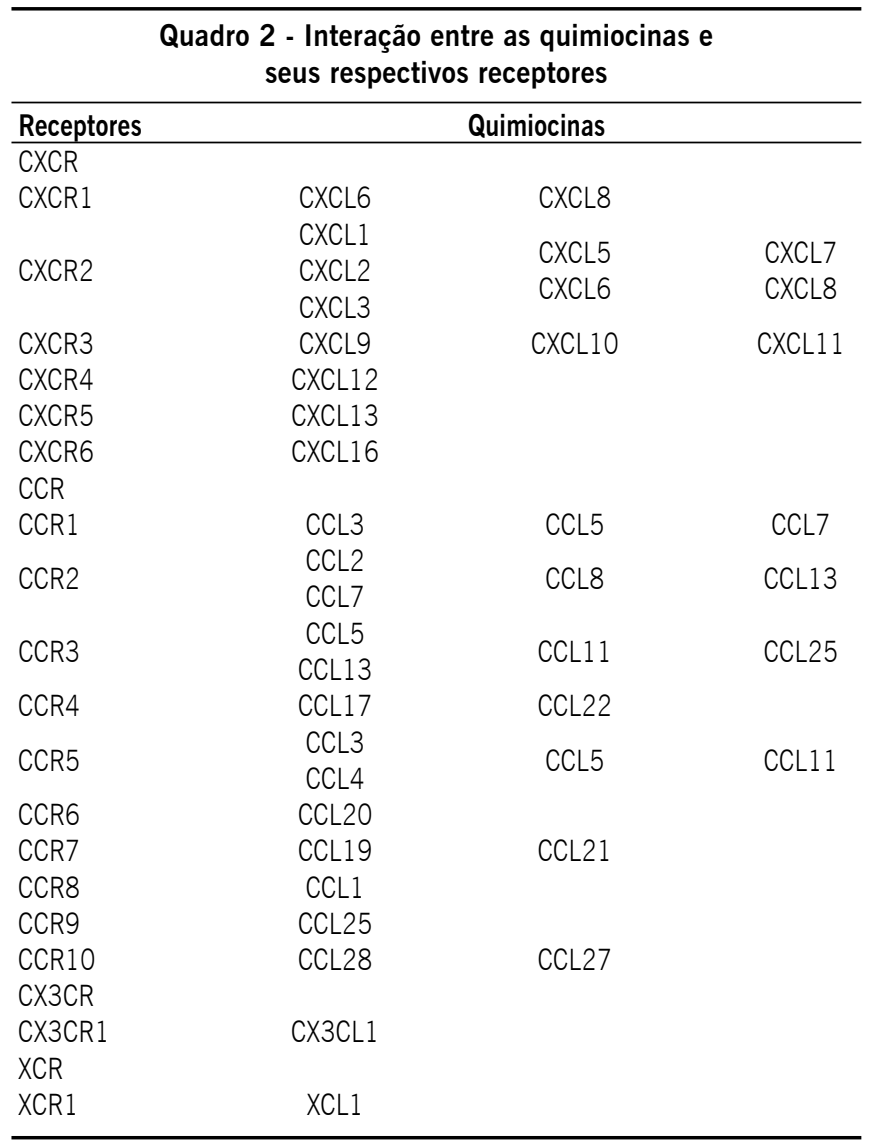

Quimiocinas dos receptores CXCR1 e CXCR2

Estes receptores estão presentes principalmente em neutrófilos e monócitos. CXCL6 e CXCL8 são quimiocinas que se ligam aos receptores e estão envolvidas com processos inflamatórios neutrofílicos. A expressão dos receptores CXCR1 e CXCR2 está aumentada nos pacientes com DPOC ${ }^{60}$. A inibição desses receptores está relacionada à diminuição da inflamação neutrofílica em modelo experiemental ${ }^{60}$.

\section{Quimiocinas do receptor CXCR3}

O receptor CXCR3 é compartilhado pelas quimiocinas monocina induzida pelo interferon (IFN)- $\gamma$ (MIG / CXCL9), proteína 10 induzida pelo IFN (IP-10 / CXCL10) e quimiotático $\alpha$ de célula $T$ induzido pelo interferon (I-TAC / CXCL11) e expresso pelos linfócitos T CD4 e CD8, linfócitos B, monócitos, macrófagos e células epiteliais ${ }^{19,61}$. O mecanismo pelo qual os linfócitos $T$ se acumulam no parênquima pulmonar e na parede das vias aéreas de pacientes com DPOC ainda não está claro. No entanto, é provável que linfócitos presentes na circulação sejam ativados e, posteriormente, sofram a ação de quimiocinas, mecanismo pelo qual eles seriam recrutados para o pulmão. Algumas evidências sugerem a participação de quimiocinas do receptor CXCR3 nesse processo. Pacientes com DPOC apresentam aumento da expressão do receptor CXCR3 nos linfócitos T e macrófagos alveolares ${ }^{19}$. Existe aumento da expressão de IP-10/CXCL10 nas células epiteliais e músculo liso no parênquima pulmonar de 
pacientes com DPOC, o que poderia contribuir para o acúmulo de células $T$, já que elas apresentam o receptor CXCR3, que se liga à IP-10/CXCL10 $10^{62}$. Os macrófagos alveolares ${ }^{61}$ e as células dendríticas ${ }^{62}$ também produzem as quimiocinas do receptor CXCR3 (MIG/CXCL9, IP-10/CXCL10 e I-TAC/CXCL11) e também poderiam participar do recrutamento linfocitário. Como os receptores CXCR3 também estão presentes nos monócitos do sangue periférico, é possível que estas quimiocinas também estejam relacionadas com o acúmulo de macrófagos alveolares, já que os monócitos são os precursores destas células. Costa et al. observaram aumento das três quimiocinas do receptor CXCR3 no escarro induzido recolhido de pacientes com DPOC quando comparado com tabagistas sem doença obstrutiva e controles não tabagistas, sugerindo a participação destas quimiocinas na inflamação crônica presente apenas em indivíduos que desenvolvem obstrução brônquica63.

Quimocinas de outros receptores CXC

As quimiocinas CXCL12 (Fator 1 derivado da célula do estroma) e CXCL13 (Quimiocina 1 da célula B) se ligam respectivamente aos receptores CXCR4 e CXCR5 ${ }^{64}$. 0 primeiro está presente nos linfócitos $T$ e células epiteliais pulmonares. Além, disso a inibição seletiva deste receptor diminui a reação inflamatória em camundongos. O receptor CXCR5 está presente nas células B e, como estas células estão aumentadas nos pacientes com DPOC grave, acredita-se que possa haver participação do receptor CXCR5 na doença grave. No entanto, não está estabelecida nem a participação destes receptores nem a do CXCR6, expresso pelos linfócitos T, que também apresentam os receptores CXCR3 e CCR5, no processo inflamatório da DPOC ${ }^{64}$.

Quimiocinas do receptor CCR5

O receptor CCR5, que pode ser encontrado nos linfócitos $T$ CD4 e CD8, monócitos e macrófagos, é utilizado pelas quimiocinas RANTES, proteína inflamatória macrofágica (MIP)-1 $\alpha$ / CCL3 e MIP-1ß/ CCL4 ${ }^{64,65}$. Assim como acontece com o receptor CXCR3, a expressão do CCR5 está aumentada nos macrófagos alveolares e nos linfócitos T presentes no parênquima pulmonar de pacientes com DPOC ${ }^{19}$. Estudos feitos com imunohistoquímica demonstraram que RANTES / CCL5 está aumentada em outros processos inflamatórios que cursam com polarização do tipo Th1, como na inflamação de tonsilas, certos tumores e na rejeição de transplantes renais ${ }^{66}$. Assim como as quimiocinas do receptor CXCR5, RANTES/CCL5 está aumentada no escarro induzido de pacientes com DPOC quando comparado com os controles tabagistas e não tabagistas ${ }^{63}$. No entanto, a interação entre estas quimiocinas e a real quimiotaxia de células inflamatórias para as vias aéreas de pacientes com DPOC ainda não foi demonstrada.

Vários estudos observaram que a expressão dos receptores CXCR3 e CCR5 está aumentada na inflamação com fenótipo 1 , como ocorre na DPOC ${ }^{19,53,66}$. Bonechi et al. verificaram que ao estimular a produção de Th1 e Th2 por meio da exposição de linfócitos de cordão umbilical à presença de IL-12 (potencilizador do padrão Th1) e inibidor de IL-4 ou à IL-4 (potencilizador do padrão Th2) e inibidor de IL-12, a produção de citocinas era bastante polarizada. Os linfócitos diferenciados no padrão Th1 produziam preferencialmente IFN- $\gamma$ enquanto que, ao contrário, as células do padrão Th2 produziam muito mais IL-4 do que IFN- $\gamma$. Através da análise da expressão de RNA mensageiro, os autores estudaram os principais receptores de quimiocinas nas duas populações celulares. A expressão do receptor CCR5 foi quase cinco vezes maior nos linfócitos do fenotipo $1 \mathrm{em}$ comparação com o outro grupo. Da mesma forma, a expressão do receptor CXCR3 foi quase sete vezes maior nas células do fenotipo 1. Estes dados sugerem que os receptores CCR5 e CXCR3 são preferencialmente expressos pelas células do fenotipo 1 , enquanto que a expressão de CCR4 é mais vista na inflamação tipo Th2 ${ }^{67}$.

Dessa forma, as células inflamatórias que expressam os receptores CXCR3 e CCR5 estariam ativadas no pulmão de pacientes com DPOC e estes receptores seriam capazes de atrair suas quimiocinas (MIG, IP-10 e I-TAC se ligando ao receptor CXCR3 e RANTES, MIP-1 $\alpha$ e MIP-1 $\beta$ ao receptor CCR5). De fato, alguns autores conseguiram demonstrar que pacientes com DPOC apresentam aumento do número de células que expressam CXCR3 e CCR5 no parênquima pulmonar ${ }^{19,28}$. Acredita-se, ainda, que as quimiocinas estariam relacionadas ao recrutamento de leucócitos presentes na circulação em direção ao local de injúria, no caso, o parênquima pulmonar e as vias aéreas de tabagistas. A chegada dessas células com o mesmo perfil inflamatório (tipo 1) seria um fator perpetuador da inflamação pulmonar e poderia ser o diferencial determinante que levaria à destruição pulmonar em uma parcela de tabagistas. No entanto, poucos autores conseguiram demonstrar fatos que corroborassem esta teoria. Cole e et al. demonstraram que I-TAC é um potente recrutador de linfócitos $T$ ativados, monócitos e neutrófilos ${ }^{68}$. Thorley et al. sugeriram o Burns et al. verificaram o aumento de influxo de células $T$ recrutadas em direção à adventícia e à média de artérias de um modelo de rejeição de transplante coronariano ${ }^{69}$. Essas células expressavam CXCR3 e CCR5.

Apesar de já existir publicações sugerindo o aumento da produção dos ligantes dos receptores CXCR3 e CCR5 no pulmão de pacientes com DPOC, ainda não foi possível confirmar que as células da circulação possam ser recrutadas para o pulmão por meio do efeito dessas quimiocinas.

\section{Conclusão}

Atualmente, não existe tratamento que atue no processo inflamatório da DPOC ou na sua progressão. O melhor entendimento da fisiopatologia desta doença pode ajudar a propor novas abordagens terapêuticas. Vários antagonistas dos mediadores inflamatórios têm sido testados ainda sem sucesso. 0 estudo de antagonistas dos receptores CXCR2 e CXCR3, os quais atuariam inibindo o recrutamento de neutrófilos e linfócitos, respectivamente, podem ser promissores ${ }^{63,70}$. Terapias anti-TNF- $\alpha$ também têm sido estudadas ainda sem resultado conclusivo ${ }^{71}$. Outra possibilidade é a resolução da resistência aos glicocorticoides por meio do uso de medicamentos antioxidantes ${ }^{70}$.

\section{Conflito de interesse: não há}

\section{SUMMARY}

INFLAMMATORY CELLS AND THEIR MEDIATORS IN COPD PATHOGENESIS

Chronic Obstructive Pulmonary Disease (COPD) is considered to be a progressive disease characterized by chronic inflammation and irreversible airflow obstruction, mainly caused 
by tobacco smoking. Based on World Health Organization data, COPD will be the fourth cause of mortality in 2020, after vascular, cardiac and cerebral diseases and cancer. To date no therapy retards or suppresses progression of COPD. The chronic inflammatory process caused by tobacco smoking promotes structural changes predominantly in the small airways (less than $2 \mathrm{~mm}$ ). Macrophages, neutrophils and T cells are thought to be important key players, as well as structural cells like fibroblasts, epithelial and smooth muscle cells. The interaction between macrophages and lymphocytes, especially CD8+, has been implicated in the pathogenesis of COPD. Chemokines such as CXCL9/MIG, CXCL10/IP-10, CXCL11/I-TAC and CCL5/ RANTES have been described as possibly responsible for recruitment of $T$ cells and blood monocytes increasing the number of macrophages and CD8 $+T$ cells in the lung of COPD patients. The study of the influx of mononuclear cells to the lung is very important not only to promote a better understanding of the COPD physiopathology but also to help identify new targets for treatment. Based on this new evidence, the study of several mediator antagonists that can block the recruitment of inflammatory cells to the lung have been tested in COPD. [Rev Assoc Med Bras 2009; 55(3): 347-54]

KEY WORDS: COPD. Inflammation. Chemokines.

\section{REFERÊNCIAS}

1. Barnes PJ. Immunology of asthma and chronic obstructive pulmonary disease. Nat Rev Immunol. 2008;8:183-92.

2. Corless J.The aetiology and epidemiology of chronic obstructive pulmonary disease. In: Pearson M, Wedzicha W. Chronic obstructive pulmonary disease. Critical debates. Massachusetts: Blackwell Science; 2003. p.1-16.

3. Celli BR. Chronic obstructive pulmonary disease. From unjustified nihilism to evidence-based optimism. Am Thorac Soc. 2006;3:58-65.

4. Lopes AD, Murray CC. The global burden of disease. 1990-2020. Nat Med. 1998;4:1241-3.

5. Menezes AM, Perez-Padilla R, Jardim JR, Muiño A, Lopez MV, Valdivia G, et al. Chronic obstructive pulmonary disease in five Latin American cities (The PLATINO study): a prevalence study. Lancet. 2005;366:1875-81.

6. Burrows B, Bloom JW, Traver GA, et al. The course and prognosis of different forms of chronic airways obstruction in a sample of general population. $N$ Engl J Med. 1987;317:1309-14.

7. Wouters E. Local and systemic inflammation in chronic obstructive pulmonary disease. Proc Am Thorac Soc. 2005;2:26-33.

8. Kim V, Rogers TJ, Criner GJ. New concepts in the pathobiology of chronic obstructive pulmonary disease. Proc Am Thorac Soc. 2008;5:478-85.

9. Cosio MG, Majo J, Cosio M. Inflammation in the airways and lung parenchyma in COPD. Role of T cells. Chest. 2002;121(5 suppl):160S-5S.

10. Rufino R, Costa $\mathrm{CH}$, Souza HS, Madi K, Silva JR. Perfil celular do escarro induzido e sangue periférico na doença pulmonar obstrutiva crônica. J Bras Pneumol. 2007;33:510-8.

11. Hardaker EL, Bacon AM, Carlson K, Roshak AK, Foley JJ, Schmidt DB, et al. Regulation of TNF- and IFN- induced CXCL10 expression: participation of the airway smooth muscle in the pulmonary inflammatory response in chronic obstructive pulmonary disease. FASEB J. 2004;18:191-3.

12. Panzner P, Lafitte JJ, Tsicopoulos A, Hamid Q, Tulic MK. Marked up-regulation of $T$ lymphocytes and expression of interleukin- 9 in bronchial biopsies from patients with chronic bronchitis with obstruction. Chest. 2003;124:1909-15.

13. Traves SL, Smith SJ, Barnes PJ, Donnely LE. Specific CXC but not CC chemokines cause elevated monocyte migration in COPD: a role for CXCR2. J Leukoc Biol. 2004;76:441-50.

14. Selman M, Cisneros-Lira J, Gaxiola M, Ramírez R, Kudlacz EM, Mitchell PG, et al. Matrix mielloproteinases inhibition attenuates tobacco smoke-induced emphysema in guinea pigs. Chest. 2003;123:1633-41.

15. Chung KF, Adcock IM. Multifaceted mechanisms in COPD: inflammation, immunity, and tissue repair and destruction. Eur Respir J. 2008;31:1334-56.

16. Sampsonas F, Kaparianos A, Lykouras D, Karkoulias K, Spiropoulos K. DNA sequence variations of metalloproteinases: their role in asthma and COPD. Postgrad Med J. 2007;83:244-50.
17. Le Quément C, Guénon I, Gillon JY, Valença S, Cayron-Elizondo V, Lagente V, et al. The selective MMP-12 inhibitor, AS1 11793 reduces airway inflammation in mice exposed to cigarette smoke. Br J Pharmacol. 2008;154:1206-15.

18. Shapiro SD. The macrophage in chronic obstructive pulmonary disease. Am J Respir Crit Care Med. 1999;160(5 pt 2):S29-S32.

19. Grumelli S, Corry DB, Song LZ, Song L, Green L, Huh J, et al. An immune basis for lung parenchymal destruction in chronic pulmonary disease and emphysema. PLoS Med. 2004;1:75-83.

20. Culpitt SV, Rogers DF, Shah P, De Matos C, Russel RE, Donnelly LE, et al. Impaired inhibition by dexamethasone of cytokine release by alveolar macrophages from patients with chronic obstructive pulmonary disease. Am J Respir Crit Care Med. 2003;167:24-31.

21. Ito K, Lim S, Caramori G, Chung KF, Barnes PJ, Adcock IM. Cigarette smoking reduces histone deacetylase 2 expression, enhances cytokine expression and inhibits glucocorticoid actions in alveolar macrophages. FASEB J. 2001;15:1110-2.

22. Finkelstein R, Fraser RS, Ghezzo H, Cosio MG. Alveolar inflammation and its relation to emphysema in smokers. Am J Respir Crit Care Med. 1995; 152 (5 Pt 1): 1666-72.

23. Freeman CM, Curtis JL, Chensue SW. CC chemokine receptor 5 and CXC chemokine receptor 6 expression by lung CD8 cells correlates with chronic obstructive pulmonary disease severity. Am J Pathol. 2007;171:767-76.

24. Saetta M, Di Stefano A, Turato G, Facchini FM, Corbino L, Mapp CE, et al. CD8 T-lymphocytes in the epithelial airways of smokers with chronic pulmonary disease. Am J Respir Crit Care Med. 1998;157(3 Pt 1):822-6.

25. Takubo Y, Guerassimov A, Ghezzo H, Triantafillopoullos A, Bates JH, Hoidal JR, et al. Alpha 1-Antitrypsin determines the pattern of emphysema and function in tobacco smoke-exposed mice: parallels with human disease. Am J Respir Crit Care Med. 2002;166 (12 Pt 1):1596-603.

26. Retamales I, Elliott WM, Meshi B, Coxson HO, Pare PD, Scuba FC, et al. Amplification of inflammation in emphysema and its association with latent adenoviral infection. Am J Respir Crit Care Med 2001;164:469-73.

27. Majo J, Ghezzo H, Cosio MG. Lymphocyte population and apoptosis in the lung of smokers and their relation to emphysema. Eur Respir J. 2001;17:946-53.

28. Saetta M, Mariani M, Panina-Bordignon P, Turato G, Buosanti C, Baraldi S, et al. Increased expression of the chemokine receptor CXCR3 and its ligand CXCL10 in peripheral airways in smokers with chronic obstructive pulmonary disease. Am J Respir Crit Care Med. 2002;165:1404-9.

29. Tanino M, Betsuyaku T, Takeyabu K, Tanino Y, Yamaguchi E, Miyamoto K, et al. Increased levels of interleukin 8 in BAL fluid from smokers susceptible to pulmonary emphysema. Thorax. 2002; 57:405-11.

30. Hulbert WM, McLean T, Hogg JC. The effect of acute airway inflammation on bronchial reactivity in guinea pigs. Am Rev Respir Dis. 1985;132:7-11.

31. Holz O, Seiler T, Karmeier A, Fraedrich J, Leiner H, Magnussen H, et al. Assessing airway inflammation in clinical practice - experience with spontaneous sputum analysis. BMC Pulm Med. 2008; 28:5.

32. Lapperre TS, Willems LN, Timens W, Rabe KF, Hiemstra PS, Postma DS, et al. Small airways dysfunction and neutrophilic inflammation in bronchial biopsies and BAL in COPD. Chest. 2007;131:53-9.

33. Breuer R, Christensen TG, Lucey EC, Stone PJ, Snider GL. An ultrastructural morphometric analysis of elastase-treated hamster bronchi shows discharge followed by progressive accumulation of secretory granules. Am Rev Respir Dis. 1987; 136:698-703.

34. ODonnell R, Breen D, Wilson S, Djukanovic. Inflammatory cells in the airways in COPD. Thorax. 2006;61:448-54.

35. Gottlieb DJ, Stone PJ, Sparrow D, Gale ME, Weiss ST, Snider GL, et al. Urinary desmosine excretion in smoker with and without rapid decline of lung function: the Normative Aging Study. Am J Respir Crit Care Med. 1996;154:1290-5.

36. Black PN, Ching PS, Beaumont B, Ranasinghe S, Taylor G, Merrilees MJ. Changes in elastic fibres in the small airways and alveoli in COPD. Eur Respir J. 2008; 31:998-1004.

37. Rufino R, Madi K, Souza HSP, Costa CH, Saito E, Lapa e Silva JR. Avaliação quantitativa das fibras elásticas na doença pulmonar obstrutiva crônica. J Bras Pneumol. 2007;33:502-9.

38. Bosken $\mathrm{CH}$, Hards J, Gatter K, Hogg JC. Characterization of the inflammatory reaction in the peripheral airways of cigarette smokers using immunocytochemistry. Am Rev Respir Dis. 1992;145:911-7.

39. Turato G, Zuin R, Saetta M. Pathogenesis and pathology of COPD. Respiration. 2001;68:117-28.

40. Saha S, Brightling CE. Eosinophilic airway inflammation in COPD. Int J Chron Obstruct Pulmon Dis. 2006;1:39-47.

41. Fujimoto K, Kubo K, Yamamoto H, Yamaguchi S, Matzuzawa Y. Eosinophilic inflammation in the airway is related to glucocorticoid reversibility in patients with pulmonary emphysema. Chest. 1999;115:697-702.

42. Brightling CE, Monteiro W, Ward R, Parker D, Morgan MD, Wardlaw AJ, et al. Sputum eosinophilia and short-term response to prednisolone in chronic obstructive pulmonary disease: a randomized controlled trial. Lancet. 2000; 356:1480-5. 
43. Saetta M, Di Stefano A, Maestrelli P, Turato G, Ruggieri MP, Roggeri A, et al. Airway eosinophilia in chronic bronchitis during exacerbations. Am J Respir Crit Care Med. 1994;150:1646-52.

44. Liu H, Lazarus SC, Caughey GH, Fahy JV. Neutrophil elastase and elastase-rich cystic fibrosis sputum degranulate human eosinophils in vitro. Am J Physiol. 1999;276:28-34

45. Holt PG, Stumbles PA. Regulation of immunologic homeostasis in peripheral tissues by dendritic cells: the respiratory tract as a paradigm. J Allergy Clin Immunol. 2000;105:421-9.

46. Zeid NA, Muller HK. Tobacco smoke induced lung granulomas and tumors: association with pulmonary Langerhans cells. Pathology. 1995;27:247-54.

47. Casolaro MA, Bernaudin JF, Saltini C, Ferrans VJ, Chrystal RG. Accumulation of Langerhans cells on the epithelial surface of the lower respiratory tract in normal subjects in association with cigarette smoking. Am Rev Respir Dis. 1988; 137:406-11.

48. Floreani AA, Wyatt TA, Stoner J, Sanderson SD, Thompson ED, Allen-Gimpson $D$, et al. Smoke and C5a induce airway epithelial ICAM-1 and cell adhesion. Am J Respir Cell Mol Biol. 2003; 29:472-82.

49. Chung KF. Cytokines in chronic obstructive pulmonary disease. Eur Respir J. 2001;34(Suppl): 50S-9S.

50. Chung KF, Barnes PJ. Cytokines in asthma. Thorax. 1999;54:825-57.

51. Barnes PJ. IL-10: a key regulator of allergic disease. Clin Exp Allergy. 1999;31: 667-9.

52. Karpus WJ, Lukacs NW, Kennedy KJ, Smith WS, Hurst SD, Barret TA. Differential CC chemokine-induced enhancement of T helper cell cytokine production. J Immunol. 1997;158:4129-36.

53. Annunziato F, Cosmi L, Galli G, Beltrame C, Romagnani P, Manetti R, et al. Assessment of chemokine receptor expression by human Th1 and Th2 in vitro and in vivo. J Leukoc Biol. 1999;65:691-9.

54. Yamagata T, Ichinose M. Agents against cytokines synthesis or receptors. Eur J Pharmacol. 2006;533:289-301.

55. Lloyd CM, Delaney T, Nguyen T, Tyan J, Martinez A-C, Coyle AJ, et al. CC chemokine receptor (CCR)3/eotaxin is followed by CCR4/monocyte-derived chemokine in mediating pulmonary T helper lymphocyte type 2 recruitment after serial antigen challenge in vivo. J Exp Med. 2000;191:265-74.

56. Woolhouse IS, Bayley DL, Stockley RA. Effect of sputum processing with dithiothreitol on the detection of inflammatory mediators in chronic bronchitis and bronchiectasis. Thorax. 2002;57:667-71.

57. Gompertz S, OBrien C, Bayley DL, Hill SL, Stockley AR. Changes in bronchial inflammation during acute exacerbations of chronic bronchitis. Eur Respir J. 2001;17:1112-9.

58. Traves SL, Culpitt S, Russell RE, Barnes PJ, Donnely LE. Elevated levels of the chemokines GRO- and MCP-1 in sputum samples from COPD patients. Thorax. 2002;57:590-5

59. Qiu Y, Zhu J, Bandi V, Atmar RL, Hattotuwa K, Guntupalli KK, et al. Biopsy neutrophilia, neutrophil chemokine and receptor gene expression in severe exacerbations of chronic obstructive pulmonary disease. Am J Respir Crit Care Med. 2003;168:968-75.

60. Folkerts G, Kraneveld AD, Nijkamp FP.New endogenous CXC chemokine ligands as potential targets in lung emphysema. Trends Pharmacol Sci. 2008;29:181-5.

61. Hardaker EL, Bacon AM, Carlson K, Roshak AK, Foley JJ, Schmidt DD, et al. Regulation of TNF- and IFN- induced CXCL10 expression: participation of the airway smooth muscle in the pulmonary inflammatory response in chronic obstructive pulmonary disease. FASEB J. 2004;18:191-3

62. Padovan E, Spagnoli GC, Ferrantini M, Heberer M. IFN-2a induces IP-10/ CXCL10 and MIG/CXCL9 production in monocyte-derived dendritic cells and enhances their capacity to attract and stimulate CD8 effector T cells. J Leukoc Biol. 2002;71:669-76.

63. Costa CH, Rufino R, Traves SL, Lapa e Silva JR, Barnes PJ, Donnelly LE. CXCR3 and CCR5 chemokines in induced sputum from patients with COPD. Chest. 2008;113:26-33.

64. Donnelly LE, Barnes PJ. Chemokines receptors as therapeutic targets in chronic obstructive pulmonary disease. Trends Pharmacol. 2006;27:546-53.

65. Ma B, Kang MJ, Lee CG, Chapoval S, Liu W, Chen Q, et al. Role of CCR5 in IFN- $\gamma$-induced and cigarette smoke-induced emphysema. J Clin Invest .2005; 115:3460-72.

66. Stanford MM, Issekutz TB. The relative activity of CXCR3 and CCR5 ligands in T lymphocyte migration: concordant and disparate activities in vitro and in vivo. J Leukoc Biol. 2003; 74:791-9.

67. Bonecchi R, Bianchi G, Bordignon PP, DAmbrosio D, Lang R, Borsatti A, et al. Differential expression of chemokine receptors and chemotactic responsiveness of Type 1 T helper cells (Th1s) and Th2s. J Exp Med. 1998;187:129-34.

68. Cole KE, Strick CA, Paradis TJ, Ogborne KT, Loetscher M, Gladue RP, et al. Interferon-inducible T cell alpha chemoattractant (I-TAC): a novel non-ELR CXC chemokine with potent activity $T$ cells through selective high affinity binding to CXCR3. J Exp Med. 1998;187:2009-21.

69. Burns WR, Wang Y, Tang PC, Ranjbaran H, lakimov A, Kim J, et al. Recruitment of CXCR3 and CCR5 T cells and production of interferon- $\gamma$-inducible chemokines in rejecting human arteries. Am J Transplant. 2005;5:1226-36.

70. Barnes PJ. Frontrunners in novel pharmacotherapy of COPD. Curr Opin Pharmacol. 2008:8:300-7.

71. AntoniuSA, Mihaltan F, Ulmeanu R. Anti-TNF-alphatherapiesinchronicobstructive pulmonary diseases. Expert Opin Investig Drugs. 2008;17:1203-11.

Artigo recebido: 24/03/08 Aceito para publicação: 16/09/08 